\title{
CONSIDERAÇÕES SOBRE A PRÁTICA DA LEITURA E DA ESCRITA
}

Márcia da Gama Silva Felipe (UERJ)

Resumo: As avaliações em grande escala, desenvolvidas com o objetivo de medir o nível de proficiência dos estudantes, têm apresentado resultados nada satisfatórios para a educação brasileira. Não obstante a proliferação de gêneros textuais e a democratização do acesso às redes sociais, a habilidade no uso da Língua Portuguesa continua preocupante. Por isso, leitura e produção textual são temas garantidos em debates dentro e fora da Academia. Com o objetivo de desenvolver algumas reflexões em torno do assunto, reúnem-se neste artigo as propostas de alguns pesquisadores, cujas produções têm enriquecido as investigações nesse campo da aprendizagem. Bakhtin (2011), Guedes (2009), Pennac (1993) e Simões (2009) trazem contribuições importantes acerca de três pontos: o domínio do código linguístico, o dialogismo intrínseco ao discurso e o prazer da leitura. As propostas desses autores são aplicadas no texto-corpus, a partir do qual pode-se comprovar a pertinência das teorias apresentadas para o desenvolvimento da capacidade de leitura e escrita.

Palavras-chave: Leitura; Produção-textual; Dialogismo; Proficiência.

Abstract: Large-scale evaluations developed in order to mesure the proficiency level of the students have shown insufficient results in Brazilian education. Despite the proliferation of textual genres and the democratization of the access to the social networks, the ability to use the Portuguese Language remains worrying. For this reason, reading and textual production are themes confirmed in debates within and without the Academy. Aiming to develop some reflections about the object, this article presents proposals by researchers whose production have improved the investigations on that learning field. Bakhtin (2011), Guedes (2009), Pennac (1993) and Simões (2009) bring important contributions concerning three points: the linguistic code knowledge, the intrinsec dialogism of discourse and the pleasure of reading. The proposals of these authors are applied in the text-corpus from which it can prove the relevancy of the theories presented for the development of the reading and writing abilities.

Keywords: Reading; Textual production; Dialogism; Proficiency. 


\section{INTRODUÇÃO}

O "pleno desenvolvimento da pessoa" assim como "seu preparo para o exercício da cidadania" são direitos garantidos pela Constituição Federal. Também previstos no artigo 20 da Lei de Diretrizes e Bases da Educação Nacional (LDB), esses direitos encontram no ambiente escolar o seu maior aliado. Desse modo, não há como dissociar o aprendizado da leitura e da escrita do desenvolvimento da pessoa nem do efetivo exercício da cidadania. A despeito do fato de que o espaço educativo não se restringe aos bancos escolares, o ambiente da sala de aula continua sendo o lugar sobre o qual recai grande parte dessa responsabilidade.

Esses dois aspectos da aprendizagem deixaram de ser privilégio dos bancos escolares, principalmente com o advento da Internet e das redes sociais. A despeito do grande desenvolvimento tecnológico, da considerável participação de jovens e adultos nesse universo interativo e das inúmeras possibilidades de leitura e produção de texto, é inegável o baixo potencial de leitura e produção textual de grande parte da sociedade. Os níveis de leitura e produção textual do alunado das escolas públicas brasileiras (principalmente nas redes estadual e municipal) estão abaixo de um valor médio considerado razoável pelos índices oficiais. Essa 
realidade tem-se perpetuado nos resultados divulgados por órgãos nacionais e internacionais desde o início da aferição dos resultados das avaliações em grande escala.

Justifica-se, pois, a frequente preocupação de estudiosos da educação em torno do assunto, o que faz com que os debates sejam permanentes. Propostas, projetos e teorias diversas buscam não apenas identificar as causas dessa dificuldade, mas também apontar caminhos com vistas a mudar ou, pelo menos, minimizar as dificuldades refletidas nesse quadro no desempenho escolar. Em função disso, o objetivo desse trabalho é trazer à luz algumas considerações apresentadas por especialistas da área, a fim de que se possa contribuir para o enriquecimento do debate.

Importa, primeiramente, conhecer a realidade nacional no quesito leitura, com base nos resultados das avaliações em grande escala. Num segundo momento serão apresentadas as reflexões de alguns pesquisadores, cujos textos servem de base teórica para as análises aqui desenvolvidas. Posteriormente, a partir de um corpus selecionado, serão testadas algumas hipóteses apresentadas pelos teóricos pesquisados. Para iniciar as investigações, passa-se à leitura dos dados oficiais divulgados na página do Instituto Nacional de Estudos e Pesquisas Educacionais (INEP), órgão oficial 
responsável pela aplicação de avaliações em grande escala e pela divulgação dos resultados.

\section{ANÁLISE DOS RESULTADOS}

O Instituto Nacional de Estudos e Pesquisas Educacionais (INEP) realizou a 13ạ versão do Sistema de Avaliação da Educação Básica (SAEB), cujo resultado foi divulgado em setembro de 2016. Esses resultados demonstram o baixo rendimento dos alunos de Ensino Fundamental e Médio na disciplina de Língua Portuguesa. Os gráficos anexos a esta pesquisa apresentam a evolução dos resultados do SAEB com base nos anos de 2013 e 2015, em todos os Estados, assim como a média nacional. Os dados são das proficiências médias em Língua Portuguesa equivalentes aos anos 5으 e 9으 do Ensino Fundamental e ao 3o ano do Ensino Médio. Serão privilegiados observados aqui os resultados do Estado do Rio de Janeiro, comparados à média nacional.

Os níveis de proficiência são medidos da seguinte forma: de 0 a 350 no 5ㅇ ano, divididos em 9 níveis. O 9o ano vai de 200 a 400 divididos em 8 níveis. Os níveis de proficiência do 3ㅇ ano começam a ser medidos em 220 pontos indo até 425, distribuídos em 8 níveis. Vale destacar que, como o início da contagem e a quantidade de níveis variam nos segmentos escolares analisados, varia também a pontuação 
dos intervalos. Outro dado importante a se ressaltar é que, segundo a tabela oficial "O intervalo do nível inclui o primeiro ponto e exclui o último". Os dados a seguir apresentam a média dos resultados, respectivamente nos anos de 2013 e 2015.

- 5 ano - 202 e 212. Esses resultados são referentes ao nível 4 (200-225) de proficiência (de um total de 9). A média nacional saiu do nível 3 (175-200) em 2013 para o nível 4 em 2015 com um resultado de 196 e 208, respectivamente;

- $\quad$ 9o ano - 249 e 254. Esse ano de escolaridade saiu do nível 2 (225250), em 2013 para o nível 3 (250-275) em 2015 (de um total de 8 níveis). O mesmo ocorreu com a média nacional que foi de 246 e 252, respectivamente;

- 3o ano do Ensino Médio - 277 e 276. Esses resultados equivalem ao nível 3 (275-300). Enquanto a média nacional resultou em 264 e 267, referentes ao nível 2 (250-275).

A análise dos dados constata a precariedade dos níveis de proficiência dos alunos das escolas brasileiras. A título de informação, importa ainda apresentar a porcentagem de alunos em cada nível de proficiência. Esses dados mostram a porcentagem mínima de alunos que alcançaram os maiores níveis de proficiência; com destaque especial para o último nível, que não alcançou nem $1 \%$ do total. Considerando que 
no ano de 2015 um total de 23.141 estudantes fizeram a prova, nem 231 alcançaram o último nível de proficiência. Observe-se que nessas informações foi acrescentado o nível 0 de proficiência. Nas informações oficiais, não foram encontrados esses dados para o 3 o ano do Ensino Médio. As tabelas a seguir apresentam as porcentagens dos resultados dentro de cada nível de proficiência. Os níveis vão de 0 a 9 no 5o ano, e de 0 a 8 no 9 o ano, na disciplina de Língua Portuguesa. Conforme se observa, na tabela a seguir, os resultados do 5ㅇa ano somaram mais de $90 \%$ até o nível 6 de proficiência. Ou seja, quase a totalidade dos alunos avaliados não apresenta um nível de proficiência elevado.

\begin{tabular}{|l|l|l|l|l|l|l|l|l|l|}
\hline \multicolumn{1}{|l|}{ LÍNGUA PORTUGUESA } \\
\hline Nível 0 & Nível 1 & Nível 2 & Nível 3 & Nível 4 & Nível 5 & Nível 6 & Nível 7 & Nível 8 & Nível 9 \\
\hline 1,65 & 6,65 & 13,37 & 18,53 & 20,41 & 18,26 & 12,09 & 5,87 & 2,2 & 0,96 \\
\hline
\end{tabular}
Tabela 1 - Porcentagem do 5ㅇano por nível de proficiência

O resultado do 9o ano, a seguir, é ainda pior. Os dados somam mais de $92 \%$ no nível de proficiência 5. Observe-se ainda a porcentagem alta nos níveis mais baixos da tabela. O nível 4 do 5o ano (200-225) equivale ao nível 1 do 9o ano (200-225). Essa informação respalda a seguinte afirmação: mais de $28 \%$ (soma dos níveis 0 e 1 ) dos alunos que saem do primeiro segmento do Ensino Fundamental não apresentam ganho significativo até o 90 ano. 


\begin{tabular}{|l|l|l|l|l|l|l|l|l|}
\hline \multicolumn{1}{|l|}{ LíNGUA PORTUGUESA } \\
\hline Nível 0 & Nível 1 & Nível 2 & Nível 3 & Nível 4 & Nível 5 & Nível 6 & Nível 7 & Nível 8 \\
\hline 16,62 & 12,19 & 16,14 & 18,76 & 17,36 & 11,8 & 5,42 & 1,51 & 0,2 \\
\hline
\end{tabular}

Tabela 2 - Porcentagem do 9a ano por nível de proficiência

A soma de todos esses dados não pode apresentar outro resultado senão a classificação do país entre os países com os piores desempenhos mundiais. Conforme informação oficial,

O Programa Internacional de Avaliação de Estudantes (Pisa), com base nos resultados da avaliação de 2015, divulgados nesta terça-feira, 6, pela Organização para a Cooperação e Desenvolvimento Econômico (OCDE), constatou que o Brasil está estacionado há dez anos entre os países com pior desempenho. O Pisa mediu o conhecimento dos estudantes de 72 países em leitura, ciências e matemática. Nas três áreas, a média dos estudantes brasileiros ficou abaixo da obtida pelos demais países. (DAEB, 2016)

Diante do exposto, não resta outra alternativa a não ser levantar novos debates em torno do tema leitura e produção textual, a fim de que se possam desenvolver ações que contribuam efetivamente para o nível de proficiência do nosso alunado. Para iniciar as análises objetivadas neste estudo, há que se delinear o embasamento teórico que dará suporte às reflexões desenvolvidas. 


\section{EMBASAMENTO TEÓRICO}

Com estudos desenvolvidos no âmbito da leitura e produção de textos, os teóricos eleitos são essenciais para as reflexões aqui desenvolvidas. Bakhtin (2011), Guedes (2009), Simões (2009) e Pennac (1993), trazem contribuições importantes para o debate. Suas considerações possibilitam a identificação de falhas e apontam caminhos para um trabalho produtivo nas aulas de Língua Portuguesa. Essas contribuições servem de base para o aumento dos níveis de proficiência citados, também observados nas aulas de Língua Portuguesa. Deve-se acrescentar que a fundamentação percorrerá toda a análise do corpus, de modo que, não serão esgotadas todas as informações teóricas nesta parte do artigo.

Frequentemente os textos produzidos pelos alunos padecem de defeitos como imprecisão e ambiguidade. Essas características podem resultar tanto da inabilidade com os recursos gramaticais quanto da ausência da alteridade, no momento da produção textual. Dessa forma, traz-se a contribuição de Mikhail Bakhtin, cujas reflexões encontradas em Estética da criação verbal (2011) ressaltam o caráter dialógico inerente ao discurso. Não raramente, a produção escrita das aulas de Língua Portuguesa tem como objetivo 
final a conquista/atribuição de uma nota. Nesse contexto, o professor exerce o papel de único leitor. Em função disso, o aluno limita-se a escrever, quando o faz, para alcançar um mínimo necessário à sua "aprovação". Acrescentando-se a esse quadro o baixo nível de leitura dos alunos, tem-se como resultado o completo distanciamento das características básicas para uma produção com um mínimo de qualidade.

A ausência da prática leitora é um dos pontos complicadores nesse processo. A relação do falante com o conteúdo representa a condição básica para produção de enunciados. Segundo o autor de Estética da criação verbal, essa relação subjaz à expressividade determinante na "escolha dos recursos lexicais, gramaticais e composicionais do enunciado" (BAKHTIN, 2011, p.289). Ou seja, se não há uma relação do falante com o objeto, se não há prática de leitura, o elemento expressivo resta prejudicado. O processo discursivo é basicamente reflexo de outros discursos. Segundo ele, "Nosso discurso [...] é pleno de palavras dos outros, de um grau vário de alteridade ou de assimilabilidade" (BAKHTIN, 2011, p.294-295).

A "escolha dos recursos lexicais", mencionada por Bakhtin, vai ao encontro das contribuições de Simões no âmbito da leitura e produção textual. Desse modo o corpus 
selecionado será analisado com base na Teoria da Iconicidade Verbal (SIMÕES, 2009). Essa teoria (doravante TIV) destaca a importância da seleção das palavras nos processos de leitura e produção textual. Segundo a pesquisadora, a iconicidade lexical refere-se ao "potencial de ativação de imagens mentais" (SIMÕES, 2009, p.86). No que toca o processo de leitura, atesta Simões que o poder icônico do léxico evidencia uma trilha de significação a ser seguida pelo leitor do texto a fim de se apropriar da mensagem lida. Por outro lado, o cabedal de leitura permite ao produtor do texto, nos níveis paradigmático e sintagmático, a seleção e organização de palavras que encaminharão o leitor nesse processo. Desse modo, leitura e produção textual são processos que precisam se desenvolver simultaneamente, visto que se retroalimentam. Para Simões, o "itinerário para leitura" é apresentado pelos signos organizados no tecido textual. Esses signos funcionam como ícones, índices ou símbolos; "quando 'desenham' o que exprimem e favorecem a dedução"; "quando conduzem processo indutivo de interpretação"; ou "quando permitem que o texto seja inserido em áreas ou subáreas temáticas, construindo o mecanismo da síntese", respectivamente (SIMÕES, 2009, p.100). 
Com base nessas informações, pode-se perceber o quanto a deficiência na decifração do código linguístico e, consequentemente, o baixo índice de leitura é prejudicial ao desenvolvimento da proficiência de nossos alunos. Nessa vertente, traz-se ao texto a preciosa contribuição de Pennac (1993), quanto ao prazer da leitura. Nos capítulos iniciais de Como um romance, o autor retrata uma época em que o ato da leitura era um ato de subversão, vinha do simples prazer de ler e não de uma obrigação imposta. Poeticamente, Pennac narra o afastamento desse prazer. Inicialmente construído no ato de leitura paterna na companhia do filho recémchegado e o gradativo afastamento, quando o pequeno, iniciada a capacidade de tradução do código linguístico, é desafiado a caminhar "com as próprias pernas". Como num ato de desabafo, o autor declara:

Nós nos deixamos ficar cegos por esse entusiasmo? Acreditamos que bastaria a uma criança o prazer das palavras para dominar os livros? Pensamos que a aprendizagem da leitura iria por si mesma, como vão a marcha vertical ou a linguagem - resumindo, um outro privilégio da nossa espécie? O que quer que seja, é o momento que escolhemos para pôr fim às leituras noturnas. (PENNAC, 1993, p.45) 
Soltam-se as mãos dos pequenos, mal começam a dar os primeiros passos nos desafios da leitura. "Ele estava grande, agora, podia ler sozinho, caminhar sozinho no território dos signos" (PENNAC, 1993, p.45). A perda do prazer da leitura é associada pelo autor ao aumento das exigências impostas por pais e professores quanto ao que foi entendido pelas crianças durante a leitura do texto. Para o autor de Como um romance, a solução para esse problema é não exigir nada em troca do ato de leitura. "Não fazer a menor pergunta. Não passar o menor dever. Não acrescentar uma só palavra àquelas das páginas lidas" (PENNAC, 1993, p.121).

É interessante associar as reflexões desenvolvidas por Pennac com os resultados das avaliações, analisados no início deste trabalho. É justamente na passagem do primeiro segmento do Ensino Fundamental - tempo em que é desenvolvida a capacidade de leitura e durante o qual ainda pode haver o prazer do ato em si - para o segundo segmento que se observa a perda do prazer de ler. É também nesse período em que caem os níveis de proficiência, ou melhor, ficam estagnados para grande parte do alunado.

Para finalizar a contribuição teórica, serão trazidas ao texto as propostas de Guedes (2009) quanto à construção da produção escrita. A despeito do fato de que, de modo geral, 
o texto aborda a produção de texto no nível superior de escolaridade, acredita-se que são exemplos relevantes que podem contribuir com qualquer nível de escolaridade. Com base em experiência própria, esse pesquisador propõe um roteiro de atividades com o objetivo de ensinar a produção escrita com mais tranquilidade com base no saber prévio dos alunos. Para o pesquisador, a leitura da palavra escrita deve ser ensinada ao aluno posteriormente à "leitura do mundo" (GUEDES, 2009, p.17). A despeito da preocupação com a forma do texto, Guedes considera mais importante concentrar a atenção em seu conteúdo. Para o pesquisador,

As perguntas fundamentais que um autor deve fazer a si mesmo antes de escrever são estas: que problema estou tentando resolver? qual meu objetivo? de que maneira quero que meu público modifique seu comportamento depois de ter lido meu texto? que novo conhecimento desejo que ele adquira? que novas atitudes ou crenças? que estados emocionais? (GUEDES, 2009, p.32)

Das questões levantadas por Guedes, duas chamam a atenção: "qual meu objetivo?" e "de que maneira quero que meu público modifique seu comportamento depois de ter lido meu texto?". Como já citado neste trabalho, o objetivo principal da produção de texto em sala de aula é 
a obtenção de nota. Dessa forma, objetivos outros são anulados na mente do aluno. A segunda questão retoma a questão da alteridade: o aluno tem apenas o professor como leitor. Logo não deve constar de seus objetivos, se é que os tem, modificar-lhe o comportamento; já que o professor é o detentor do saber. Com esses questionamentos, o pesquisador propõe que a leitura dos textos dos alunos seja incluída nas aulas de produção textual (GUEDES, 2009, p.43). Dessa forma, o público leitor não fica resumido a uma só pessoa, mas estende-se aos próprios colegas de sala, num ato de compartilhamento.

Como uma forma de "testar" os conceitos aqui apresentados, foi selecionado um texto produzido por um aluno do 5 o ano do Ensino Fundamental. Essa produção vem ao encontro das teorias aqui elencadas, corroborando a fala desses renomados teóricos. Segue-se, portanto, a apresentação do corpus.

\section{APRESENTAÇÃO E ANÁLISE DO CORPUS}

O texto - a partir do qual são desenvolvidas análises - foi elaborado por um jovem autor de 10 anos de idade, aluno do 5ㅇ ano do Ensino Fundamental, estudante da rede particular de ensino. Seu texto demonstra grande habilidade em relação às características principais do gênero narrativo: narrador, 
personagens, enredo. O texto foi transcrito exatamente como fora produzido pelo jovem autor. Destaca-se a habilidade no uso da gramática, das regras de pontuação e da formatação do texto em relação ao nível de escolaridade do autor.

Alguém

Era uma vez o Alguém. Alguém era alguém. Alguém era definitivamente alguém. Mas Alguém não era alguém qualquer, Alguém era o alguém. Sua cabeça deve estar confusa mas eu vou explicar: Alguém era um alguém especial, não qualquer alguém. Ele tinha o poder de ser alguém. Por isso, ele é o alguém e não um alguém.

Contudo, como todos os alguéns, ele faz coisas que qualquer alguém faz. Ele tinha um irmão mais novo, o Pessoa. Ele é o mesmo caso que Alguém, mas Pessoa tinha o poder de não ser uma pessoa e nem a pessoa. Ele (Alguém) tinha um irmão mais velho, o Todo Mundo, e um vizinho, chamado Nada. Todo mundo era poderoso, podendo controlar tudo, já Nada, não tem poder de nada, ele tem o poder de não ter poder. Ele tinha uma esposa, a Ninguém. Ela tinha o poder de odiar o Alguém.

H. 10 anos, março de 2017

Não serão tematizados neste estudo os poucos erros cometidos na narrativa, visto não serem relevantes em função da perfeição na articulação do texto, a coesão e 
coerência e o domínio da língua. Inicia-se essa análise com uma informação importante: o texto foi produzido espontaneamente por $H$. Não foi produção resultante de cobrança nem alvo de avaliação. Em entrevista concedida a alunos de uma turma de Doutorado, o pequeno autor disse ter produzido o texto como forma de distração. Logo, sobre essa produção não houve o peso, simplesmente o prazer da escrita, resultante do prazer da leitura.

O gênero narrativo, normalmente o primeiro com o qual os alunos mantêm contato, é bastante típico nessa idade. A produção apresenta as principais características de um texto narrativo: narrador, personagens, enredo. O conto de fadas, também um dos primeiros contatos nessa fase, marca sua presença no texto. O início é típico desse gênero, certamente já apreendido pelo autor do texto no 5으 do Ensino Fundamental. Além do clássico "Era uma vez", outras pistas serão apresentadas na análise das personagens. Contudo, um dado interessante é a descrição psicológica das personagens, feita de forma bastante criativa. Essa habilidade denota a capacidade de observação do pequeno autor. Segundo Guedes,

para que se descreva um tipo de pessoa, são necessárias observações de grupos de pessoas com vistas à depreensão de características comuns aos integrantes 
desses grupos, o que envolve formulação de hipóteses, o levantamento de dados e o raciocínio indutivo-dedutivo, atividades próprias do trabalho que leva ao texto dissertativo. (2009, p.63)

O texto com apenas dois parágrafos apresenta um poder de concisão e, ao mesmo tempo, de generalização impressionante; a seleção dos vocábulos para nomear as personagens foi essencial para esse efeito. O autor descreve vários tipos de pessoas. A análise que faz conduz à caracterização das personagens a começar pela escolha dos nomes. Não se pretende insinuar que $H$ tenha informações etimológicas dos nomes que escolheu. Quando muito, acredita-se que já tenha tido contato com as informações gramaticais. Contudo, a despeito de qualquer conhecimento teórico, os nomes não poderiam ser mais icônicos. A seguir, apresentam-se informações etimológicas que respaldam a escolha do autor.

Alguém - do latim alĭquem, "alguma pessoa", "indivíduo importante" (CUNHA, 2010), pode ser classificado como pronome ou substantivo masculino. No texto, Alguém é o personagem irmão do meio. Popularmente, o irmão do meio é aquele que recebe pouca atenção dos adultos, ou que é deixado de lado; em virtude da atenção dispensada ao irmão mais novo e das preocupações com o irmão mais 
velho. Contudo, essa expectativa é frustrada no texto, já que Alguém é dotado de uma personalidade marcante. Essa característica é denotada a partir do uso do artigo definido o Alguém, não um alguém. Nesse jogo de palavras, $H$ faz uso do pronome qualquer para corroborar sua ideia: "Mas Alguém não era alguém qualquer".

Depois de um parágrafo inteiro dedicado a Alguém, um alguém especial, símbolo de personalidade forte, o pequeno autor esclarece seu leitor que, a despeito de todas as qualidades que possui. Alguém não era ser mágico, não tem superpoderes - característica típica a personagens de conto de fadas - por isso, inicia o segundo parágrafo com uma adversativa "Contudo, como todos os alguéns, ele faz coisas que qualquer alguém faz". Definitivamente, não é um conto de fadas. O pequeno autor está pronto a se aventurar por outros gêneros textuais.

Pessoa - do latim pĕrsōna, "homem ou mulher", "personagem". A despeito do fato de considerar Pessoa como: "o mesmo caso que Alguém", o próprio narrador afirma que o irmão "tinha o poder de não ser uma pessoa e nem a pessoa". Ou seja, era um personagem. Possivelmente por ser o irmão mais novo, quem sabe um bebê, ainda em fase de crescimento, não tinha sua individualidade construída. Era conduzido ainda pelos adultos, sem vontade própria. 
Todo Mundo - o irmão mais velho é identificado por um nome composto, formado por um pronome e um substantivo. O pronome, com origem no latim tōtus, remete a "integral, inteiro"; o substantivo com origem no latim mŭndus, "o universo". A ideia de totalidade, de completude é recorrente na ótica dos irmãos mais novos, aos olhos dos quais o irmão mais velho é "aquele que pode tudo", porque conjuga idade e autorização dos pais. Símbolo de poder, "Todo mundo era poderoso, podendo controlar tudo", inclusive o vizinho Nada. Apesar de seu poder, Todo Mundo não tem espaço na narrativa, dedica-se a ele não mais que três orações.

Nada - do latim nata, originalmente "coisa nenhuma", pode ser tomado gramaticalmente como pronome ou substantivo masculino. Alcança o sentido de "nenhuma coisa", na primeira hipótese, ou de "a não existência", "ninharia", na segunda. O vizinho de Alguém, "não tem poder de nada, ele tem o poder de não ter poder". Observa-se que a iconicidade de ausência de poder também é estendida à única coisa que ele possui: sua esposa Ninguém.

Ninguém - pronome com origem no latim ne(c)quem, significa "nenhuma pessoa" - ícone de despersonalização. Contrariamente à significação do nome. Ninguém tem o "poder de odiar Alguém". O índice de negatividade 
acompanha o perfil da personagem. Ninguém representa a figura do invejoso que, por uma insatisfação pessoal, alimenta o ódio em relação a outrem: Alguém. Tipicamente a pessoa invejosa, que sofre pela felicidade alheia, personifica a madrasta ou a bruxa dos contos de fada.

\section{OUTROS DISCURSOS}

A característica dialógica do discurso é percebida no texto-corpus. Em sua narrativa, pode-se perceber um enredo bastante próximo aos contos infantis. Duas famílias que se opõem a inveja, o ódio, um jovem ou uma jovem com personalidade bastante para causar inveja a outros. Outra influência vem das histórias de super-heróis. O texto gira em torno da ideia de "poder": poder de ser, poder de controlar. Essa característica também se apresenta na formatação do manuscrito que apresenta uma marcação semelhante a uma explosão (como nos balões de fala dos quadrinhos) em torno das palavras poder e poderoso. Explicam-se essas evidências com as palavras de Bakhtin (2011),

Cada enunciado é pleno de ecos e ressonâncias de outros enunciados com os quais está ligado pela identidade da esfera de comunicação discursiva. [...] Por isso, cada enunciado é pleno de variadas atitudes responsivas a outros enunciados de dada esfera da comunicação discursiva. [...]: muito 
amiúde a expressão do nosso enunciado é determinada não só - e vez por outra não tanto - pelo conteúdo semânticoobjetal desse enunciado mas também pelos enunciados do outro sobre 0 mesmo tema, aos quais respondemos, com os quais polemizamos; [...]. (p.297)

As palavras de $H$ comprovam ainda mais a fala de Bakhtin. No encontro mencionado, do autor com uma turma de doutorandos, houve oportunidade de questioná-lo acerca de sua prática de leitura e escrita. Naquela oportunidade, apesar de assumir que "atualmente não estava lendo muito", o pequeno autor afirmou já ter lido a coleção da obra Diário de um banana. Em rápida pesquisa a esse conjunto de obras, pode-se perceber a influência dessa leitura no texto do pequeno autor. Nessa obra, a personagem principal é o irmão do meio que narra em seu diário suas aventuras. Personagem que, apesar de figurar entre o irmão mais velho, que detém certo "poder", e o irmão mais novo, centro das atenções, mantém sua personalidade marcante.

A despeito dessa influência na produção de $H$, seu texto apresenta um tom inovador, estilo machadiano, quando interpela o leitor: "Sua cabeça deve estar confusa mas eu vou explicar". Percebe-se que o pequeno autor foge ao padrão de escrita em relação à sua idade e ao momento de escolarização. 
A despeito de seu texto apresentar características inerentes ao gênero Conto de Fadas, $H$ subverte a estrutura própria desse gênero e insere seu próprio estilo. Observe-se que nesse ponto, o autor demonstra preocupação com o que - leitor apreende de sua escrita. Essa preocupação abre a possibilidade de conversa com o leitor, subvertendo o paradigma do conto de fadas. Esse recurso remete a "uma das pontas do triângulo retórico, a prática de escrever para um público" (Guedes, 2009, p.45). Essa prática permite que o autor escreva com a intenção de alcançar determinado público, não apenas para a correção do professor.

A sequência desenvolvida por Guedes para a produção textual de seus alunos pode ser perfeitamente observada no texto em foco. Quando $H$. antecipa o questionamento do leitor, tem plena consciência de que seu discurso não é jogado no vazio, mas tem direção certa. Essa consciência faz com que o autor de Alguém antecipe um possível questionamento do leitor, ao qual responde prontamente. Essa prática encontra respaldo quanto ao aspecto dialógico do discurso defendido por Bakhtin, segundo o qual a construção de enunciados deve prever objeções e antecipar respostas (BAKHTIN, 2011, p.302). 


\section{CONCLUSÃO}

Não há dúvida que a qualidade do texto-corpus é devida não só ao domínio da Língua materna, mas também à prática de leitura do pequeno autor. Do mesmo modo, não se pode negar a importância da prática de leitura para a melhora do desempenho linguístico dos alunos. Contudo, esse processo precisa ser repensado e reestruturado nas aulas de Língua Portuguesa. O peso da cobrança em torno da leitura de obras, sejam elas escolhidas livremente ou impostas, influencia negativamente no prazer da leitura. Caso esse prazer se transforme em tortura, redunda em prejuízo ao processo. Dessa forma, a responsividade discursiva não encontra eco, caso o provável escritor não seja um leitor habitual. Segundo Bakhtin, "o enunciado é um elo na cadeia da comunicação discursiva e não pode ser separado dos elos precedentes que o determinam tanto de fora quanto de dentro, gerando nele atitudes responsivas diretas e ressonâncias dialógicas" (p.300). Ser um bom leitor não garante o desenvolvimento de um bom escritor. Mas um bom escritor carece de ter um bom leitor embasando sua prática.

No processo de ensino e aprendizagem da leitura e da escrita é essencial que se ofereçam inúmeras oportunidades de leitura. Essa oferta, descompromissada num primeiro 
momento, a exemplo do que diz Pennac, contribuirá para o repertório que orientará escritas futuras. Já que a característica responsiva do discurso, ainda que não seja de forma imediata, ocorrerá. Certamente, ao processo de ensino e aprendizagem da leitura e da produção textual, dos alunos das escolas brasileiras, faltam os seguintes aspectos: o domínio das regras gramaticais, a noção da alteridade e o prazer da leitura. Segundo Bakhtin, "O papel dos outros, para quem se constrói o enunciado, é excepcionalmente grande" (2011, p.301). Caso contrário permanecerá a existência de textos incoerentes, ambíguos e inconsistentes, visto que não têm objetivos para serem escritos e não possuem um leitor real a quem sejam destinados.

\section{REFERÊNCIAS}

BAKHTIN, Mikhail (2011). Estética da criação verbal. 3.ed. São Paulo: Martins Fontes.

CUNHA, Antônio Geraldo da (2010). Dicionário etimológico da língua portuguesa. 4.ed. Rio de Janeiro: Lexikon.

DAEB. Diretoria de Avaliação da Educação Básica (2016). PISA no Brasil, 2015. Sumário Executivo. INEP. MEC. Brasília.

GUEDES, Paulo Coimbra (2009). Da redação à produção textual: o ensino da escrita. SãoPaulo: Parábola Editorial

LDB. Lei de Diretrizes e Bases da Educação (Lei 9.394/96) (2005). 9.ed. Rio de Janeiro: DP\&A.

PENNAC, Daniel (1993). Como um romance. Leny Werneck (Trad.). Rio de Janeiro: Rocco. 
SIMÕES, Darcilia (2009). Iconicidade Verbal. Teoria e prática. Dialogarts. Rio de Janeiro. In http://www.dialogarts.uerj.br. Acesso em 10.Abr.2017

Márcia da Gama Silva Felipe doutoranda em Língua Portuguesa (em curso/UERJ), Mestrado em Língua Portuguesa (UERJ/2017). Especialização em Língua Portuguesa (Liceu Literário Português/2006). Graduação e Licenciatura em Letras - Língua Portuguesa/Literaturas (UERJ/2002). Professora concursada - Secretaria Estadual de Educação do Governo do Estado do Rio de Janeiro e Secretaria Municipal de Educação do Rio de Janeiro. Atua nas disciplinas de Língua Portuguesa, Literatura e Redação. Membro do grupo de pesquisa Semiótica, Leitura e Produção de textos (SELEPROT) e da Asociación de Linguística y Filología de América Latina (ALFAL) 